\title{
Ageing and COPD affect different domains of nutritional status: the ECCE study
}

\author{
S. Battaglia*, M. Spatafora*, G. Paglino*, C. Pedone ${ }^{\#}$, A. Corsonello", N. Scichilone*, \\ R. Antonelli-Incalzi ${ }^{\#}$ and V. Bellia*
}

ABSTRACT: Chronic obstructive pulmonary disease (COPD) and ageing may contribute to malnutrition. We aimed to explore whether COPD and ageing determine malnutrition in different manners.

460 stable COPD outpatients ( 376 males and 84 females) from the Extrapulmonary Consequences of COPD in the Elderly (ECCE) study database were investigated (age 75.0 $\pm 5.9 \mathrm{yrs}$; forced expiratory volume in $1 \mathrm{~s} 54.7 \pm 18.3 \%$ predicted). Nutritional status was evaluated using the Mini Nutritional Assessment ${ }_{\circledast}$ (MNA) questionnaire. From the MNA, three scores exploring the domains of the nutritional status were calculated: body composition, energy intake and body functionality scores.

Global Initiative for Chronic Obstructive Lung Disease (GOLD) stages were negatively correlated with five MNA items exploring mobility, patient's perception of own nutrition and health status, and arm and calf circumferences (lowest Spearman's rho $(r s)=-0.011$; highest $p=0.039$ ). GOLD stages were independently correlated with body composition and body functionality scores (model $r^{2}=0.073$ ). Age was negatively correlated with four MNA items exploring loss of appetite, fluid intake, mobility and autonomy in daily life (lowest $r s=-0.013$; highest $p=0.030$ ). Age was independently correlated with body functionality score (model $r^{2}=0.037$ ).

Severe COPD and ageing are independent and probably concurrent conditions leading to malnutrition. The MNA questionnaire allows a valuable insight into the complexity of components of nutritional status and may provide useful clues for treatment strategies.

KEYWORDS: Ageing, chronic obstructive pulmonary disease, geriatric medicine, malnutrition

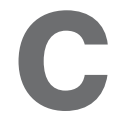
hronic obstructive pulmonary disease (COPD) is a common condition characterised by a poorly reversible limitation in airflow resulting from inflammation and remodelling of the airways [1], and many systemic effects have been recognised [2]. Amongst these, malnutrition is very common and its prevalence increases along with the severity of the disease $[3,4]$. Malnutrition has been recognised as a risk factor for mortality [5]. The relationship between malnutrition and mortality has been also confirmed in elderly COPD patients [6].

Regardless of disease status, the prevalence of malnutrition increases with age [7]; consistent with this concept, subjects aged $\geqslant 80$ yrs have a five times higher prevalence of malnutrition than subjects aged $<50$ yrs [8]. Thus, it is conceivable that COPD and ageing may contribute, in at least an additional manner, to malnutrition.
Nutritional status is the result of the interaction of food intake, absorption and utilisation of nutrients, and it is possible to define it through three variables: body composition, energy intake and body functionality [9]. Malnutrition is an overall term including: undernutrition, overnutrition, specific nutrient deficiencies and imbalance because of disproportionate intake [9]. However, in the elderly, it often refers to undernutrition [9] and it is used in this sense in the present study.

In the assessment of nutritional status, the World Health Organization (WHO) has adopted the body mass index (BMI) as the reference method to classify adults as: underweight (BMI $<18.5 \mathrm{~kg} \cdot \mathrm{m}^{-2}$ ), normal weight $\left(18.5-24.9 \mathrm{~kg} \cdot \mathrm{m}^{-2}\right)$, overweight (25$\left.29.9 \mathrm{~kg} \cdot \mathrm{m}^{-2}\right)$ or obese $\left(\geqslant 30 \mathrm{~kg} \cdot \mathrm{m}^{-2}\right)$ [10]. However, it has been demonstrated that BMI is inadequate to assess malnutrition in COPD $[11,12]$, where reduction in the fat-free mass,
AFFILIATIONS

*Dipartimento Biomedico di Medicina Interna e Specialistica, University of Palermo, Palermo, \#Dept of Geriatric Medicine, University Campus BioMedico, Rome, and

"Italian National Research Center on Aging, Consenza, Italy.

CORRESPONDENCE

S. Battaglia

Dipartimento Biomedico di Medicina Interna e Specialistica Sezione di Pneumologia University of Palermo c/o Ospedale "V. Cervello" via Trabucco 180 90146 Palermo Italy E-mail: s.battaglia@unipa.it

Received:

March 012010

Accepted after revision:

Oct 042010

First published online:

Nov 112010 
especially in patients with over-represented fat mass, may not be detected by the BMI alone. As a single variable may be inadequate to fully describe the nutritional status, questionnaires and composite indexes have been developed $[9,13,14]$. Among these diagnostic tools, the Mini Nutritional Assessment ${ }_{\circledR}$ (MNA) questionnaire has been designed and validated to provide a rapid assessment of malnutrition in elderly patients [15]. Moreover, the MNA identifies people at risk for malnutrition before severe changes in weight or albumin levels occur, and is predictive of mortality and hospital costs [15].

The characteristics and correlates of malnutrition in elderly COPD patients are still debated, and the role of ageing has not been fully elucidated. Therefore, we aimed at exploring whether COPD and ageing determine malnutrition in different manners. For this purpose, we investigated the characteristics of nutritional status by BMI and MNA questionnaire, and assessed its correlates in elderly COPD patients.

\section{METHODS}

\section{Design overview}

We analysed data from the Extrapulmonary Consequences of COPD in the Elderly (ECCE) study, a multicentre populationbased observational study of Caucasian stable COPD outpatients aged $\geqslant 65 \mathrm{yrs}$ [16]. Protocol details are reported elsewhere [16].

\section{Patients}

Participants were recruited from among those attending the pulmonary medicine outpatient clinics of 15 participating Italian centres (a full list of the participating centres can be found in the Aknowledgements). Among the 516 screened patients, 56 were excluded from the analysis because of age $<65$ yrs $(n=20)$, unconfirmed diagnosis $(n=27)$, low-quality spirometry $(n=5)$ and incomplete data on the MNA $(n=4)$. The final sample was composed of 460 patients ( 376 males and 84 females).

The diagnosis and staging of COPD was made according to American Thoracic Society/European Respiratory Society and Global Initiative for Chronic Obstructive Lung Disease (GOLD) guidelines $[1,17]$. To be included in the study, patients had to be in a stable condition and not have reported acute symptoms or therapy modifications in the 30 days before enrolment. People with a diagnosis of cancer were excluded, regardless of disease activity.

\section{Nutritional assessment}

The nutritional status was evaluated by BMI and the MNA questionnaire (online supplementary material) [15, 18]. The MNA questionnaire explores the three domains of the nutritional status: body composition, energy intake and body functionality [9]. It consists of 18 items: four explore the body composition (BMI, arm and calf circumferences, and weight loss in the previous 3 months), six explore the energy intake (number of total, proteic and vegetable- and fruit-based daily meals, reduction of appetite, hydration, and feeding autonomy) and eight explore the body functionality (number of drugs, acute events, autonomy in daily life and in transfers, pressure ulcers, cognitive status, patient's perception of his/ her own nutritional status and own health status compared to the other elderly persons) [9]. A score for each of the three nutritional domains was calculated.

The MNA questionnaire was completed according to the developers' instructions (www.mna-elderly.com). MNA is divided into a two-step procedure: the screening step and the global assessment step. According to the total score achieved (screening plus global), patients are classified as "malnourished", "at risk of malnutrition" or "well nourished". According to the conventional procedure, the "global assessment step" of the MNA should only be performed in patients not reaching the screening threshold. However, we also extended the global assessment step to patients with a score over the screening threshold. This extension was decided as an amendment to the original protocol after the study was started. As a result, the calculation of the scores for each of the three nutritional domains (body composition, energy intake and body functionality) was only obtained in 286 patients. 288 patients had a score over the screening threshold. Amongst these, 114 completed the "global assessment step" of the MNA and 174 did not; these two groups did not differ for age, BMI, Medical Research Council dyspnoea score, oxyhaemoglobin saturation, distance walked in the 6-min walking test, forced expiratory volume in $1 \mathrm{~s}$ (FEV1) \% predicted and FEV1/forced vital capacity ratio.

\section{Statistical analysis}

Statistical analysis was performed using the SPSS statistical software package, version 13.0 (SPSS Inc., Chicago, IL, USA). In descriptive analyses, data are presented as mean \pm SD or median (range) depending on their distribution, whereas when groups were compared, data are presented as mean \pm SEM. Differences between groups were evaluated by one-way ANOVA with appropriate post hoc analysis. Correlations were assessed using Pearson's coefficient (r) or Spearman's rho (rs).

Multiple ordinal regression models were performed including GOLD stages as dependent variable and as independent variables: 1) the 18 items of the MNA questionnaire; or 2) the three MNA domains. The models were corrected for age. The same approach was adopted with linear regression models, with age as dependent variable. These models were corrected for GOLD stages. Probability values of $p<0.05$ were considered to be statistically significant.

\section{RESULTS}

Anthropometric and functional characteristic of the sample are summarised in table 1 . The mean \pm SD age of enrolled patients was $75.0 \pm 5.9$ yrs and the mean FEV1 was $54.7 \pm 18.3 \%$ pred. Distribution of the sample by stage was as follows: $41(8.9 \%)$ patients in stage I, 202 (43.9\%) in stage II, 133 (28.9\%) stage III and $61(13.3 \%)$ stage IV; GOLD stage was undetermined in 23 $(5 \%)$ patients, due to lack of acceptable spirometry.

\section{Description of the nutritional status}

The mean \pm SD BMI was $27.1 \pm 5.3$ (range 14.4-51.4) $\mathrm{kg} \cdot \mathrm{m}^{-2}$. The distribution of patients according to the BMI-based WHO classification of nutritional status [10] was as follows: $14(3.0 \%)$ patients were underweight $\left(\mathrm{BMI}<18.5 \mathrm{~kg} \cdot \mathrm{m}^{-2}\right), 157(34.1 \%)$ patients had normal weight $\left(18.5-24.9 \mathrm{~kg} \cdot \mathrm{m}^{-2}\right), 168(36.5 \%)$ patients were overweight $\left(25-29.9 \mathrm{~kg} \cdot \mathrm{m}^{-2}\right)$ and $121(26.3 \%)$ patients were obese $\left(\geqslant 30 \mathrm{~kg} \cdot \mathrm{m}^{-2}\right)$. 


\begin{tabular}{lc} 
TABLE 1 & $\begin{array}{c}\text { Anthropometric and functional characteristic of } \\
\text { the whole sample }\end{array}$ \\
& \\
Patients $\mathbf{n}$ & 460 \\
Males/females $\mathbf{n}$ & $376 / 84$ \\
Age $\mathbf{y r s}$ & $75.0 \pm 5.9(65-92)$ \\
FEV $\mathbf{1} \%$ pred & $54.7 \pm 18.3$ \\
FEV $\mathbf{1} / \mathbf{F V C}$ & $0.52 \pm 0.11$ \\
Smoking exposure pack-yrs & $49.4 \pm 41.3$ \\
Sa, $\mathbf{O}_{\mathbf{2}} \%$ & $94.4 \pm 2.8$ \\
6MWT $\mathbf{~ m}$ & $311.0 \pm 129.2$ \\
BMI $\mathbf{~ k g} \cdot \mathbf{m}^{-\mathbf{2}}$ & $27.1 \pm 5.3$ \\
GOLD stage & \\
I & $41(8.9)$ \\
II & $202(43.9)$ \\
III & $133(28.9)$ \\
IV & $61(13.3)$ \\
\hline
\end{tabular}

Data are presented as mean \pm SD (range), mean \pm SD or $n(\%)$, unless otherwise stated. FEV1: forced expiratory volume in $1 \mathrm{~s}$; \% pred: \% predicted; FVC: forced vital capacity; $\mathrm{Sa}_{1} \mathrm{O}_{2}$ : arterial oxygen saturation; $6 \mathrm{MWT}$ : 6-min walking test; BMI: body mass index; GOLD: Global Initiative for Chronic Obstructive Lung Disease.

When patients were categorised according to the MNA score, $288(62.6 \%)$ patients passed the screening step of the MNA questionnaire and were immediately classified as "well nourished". After completion of the test, 31 (6.7\%) additional patients were classified as "well nourished", bringing the total number of "well nourished" patients to 319 (69.3\%); 124 $(27.0 \%)$ patients were classified as "at risk of malnutrition" and 17 (3.7\%) patients were classified as "malnourished".

Although the BMI decreases along with MNA groups (well nourished: $\mathrm{n}=319$, mean \pm SD BMI $28.3 \pm 4.8 \mathrm{~kg} \cdot \mathrm{m}^{-2}$; at risk of malnutrition: $\mathrm{n}=124$, BMI $24.9 \pm 5.2 \mathrm{~kg} \cdot \mathrm{m}^{-2}$; malnourished: $\mathrm{n}=17$, BMI $20.5 \pm 4.0 \mathrm{~kg} \cdot \mathrm{m}^{-2}$; ANOVA $\left.\mathrm{p}<0.001\right)$, there were $75(47.7 \%)$ normal, 35 (20.8\%) overweight and 17 (14\%) obese subjects classified as malnourished or at risk of malnutrition according to the MNA. These data are displayed in table 2.

Mean age did not differ between GOLD stages (table 3).

\begin{tabular}{|c|c|c|c|c|}
\hline \multirow[t]{2}{*}{ TABLE 2} & \multicolumn{4}{|c|}{$\begin{array}{l}\text { Cross-table of body mass index (BMI) versus } \\
\text { Mini Nutritional Assessment }{ }^{\circ} \text { groups }\end{array}$} \\
\hline & Malnourished & At risk & Well nourished & Total \\
\hline \multicolumn{5}{|l|}{ BMI $\mathbf{k g} \cdot \mathrm{m}^{-2}$} \\
\hline$<18.5$ & 7 & 7 & 0 & 14 \\
\hline $18.5-24.99$ & 9 & 66 & 82 & 157 \\
\hline 25-29.99 & 1 & 34 & 133 & 168 \\
\hline$\geqslant 30$ & 0 & 17 & 104 & 121 \\
\hline Total & 17 & 124 & 319 & 460 \\
\hline BMI mean \pm SD & $20.5 \pm 4.0$ & $24.9 \pm 5.2$ & $28.3 \pm 4.8$ & \\
\hline
\end{tabular}

Data are presented as $n$, unless otherwise stated. ANOVA $p<0.001$

\begin{tabular}{|c|c|c|c|c|c|}
\hline \multirow[t]{2}{*}{ TABLE 3} & \multicolumn{5}{|c|}{$\begin{array}{l}\text { Differences of body mass index (BMI) and Min } \\
\text { Nutritional Assessment }(\mathrm{MNA}) \text { total score by } \\
\text { Global Initiative for Chronic Obstructive Lung } \\
\text { Disease (GOLD) stage }\end{array}$} \\
\hline & GOLD I & GOLD II & GOLD III & GOLD IV & $\begin{array}{l}\text { ANOVA } \\
\text { p-value }\end{array}$ \\
\hline BMI $\mathrm{kg} \cdot \mathrm{m}^{-2}$ & $27.8 \pm 0.7^{*}$ & $28.1 \pm 0.4^{*}$ & $26.4 \pm 0.4$ & $24.9 \pm 0.6$ & $<0.001$ \\
\hline $\begin{array}{l}\text { MNA total } \\
\text { score }\end{array}$ & $25.1 \pm 0.7^{*}$ & $23.7 \pm 0.3$ & $23.0 \pm 0.5$ & $22.3 \pm 0.6$ & 0.020 \\
\hline Age yrs & $75.9 \pm 6.8$ & $74.8 \pm 6.1$ & $75.4 \pm 5.5$ & $73.8 \pm 5.1$ & 0.231 \\
\hline
\end{tabular}

Data are presented as mean \pm SEM, unless otherwise stated. *: $p<0.05$ in post hoc test.

\section{Nutritional characteristics of COPD}

BMI was higher in GOLD stages I and II compared with stages III and IV (ANOVA p <0.001), and the MNA total score was higher (i.e. better) in GOLD stage I compared with the other three stages (ANOVA $p=0.020)$ (table 3$)$.

When the 18 items of the MNA questionnaire were separately analysed, five of them qualified as negative correlates of GOLD stages, as follows. Question C: Mobility ( $\left.\mathrm{r}_{\mathrm{s}}=-0.11 ; \mathrm{p}=0.017\right)$; question $\mathrm{O}$ : Self view of nutritional status $(\mathrm{r} s=-0.13 ; \mathrm{p}=0.039)$; question P: In comparison with other people of the same age, how does the patient consider his/her health status? $\left(\mathrm{rs}_{\mathrm{s}}=-0.20 ; \mathrm{p}=0.001\right)$; question $\mathrm{Q}$ : Mid-arm circumference $\left(r_{s}=-0.20 ; p=0.001\right)$; question $R$ : Calf circumference $\left(r_{s}=-0.23\right.$; $\mathrm{p}<0.001$ ) (online supplementary material). Multiple ordinal regression analysis demonstrated that only questions $\mathrm{R}$ and $\mathrm{P}$ of the MNA questionnaire were independently correlated with GOLD stage $\left(\right.$ model $\mathrm{r}^{2}=0.136 ; \beta=-0.379$ and $\beta=-1.058 ; \mathrm{p}=0.036$ and $\mathrm{p}=0.004$, respectively).

We analysed the three domains of the MNA questionnaire in 286 patients. The 114 patients with a score over the screening threshold who completed the "global assessment step" of the MNA were representative of the whole sample of 288 patients with a score over the screening threshold, as described in the Methods section. While the energy intake score was the same in different GOLD stages, the body composition score was lower (i.e. worse) in GOLD stage IV and the body functionality score was lower (i.e. worse) in GOLD stages III and IV (table 4). Multiple ordinal regression analysis confirmed that body composition and body functionality scores were independently correlated with GOLD stages (table 5).

\section{Nutritional characteristics of ageing}

Age did not differ among BMI groups based on WHO classification (ANOVA $\mathrm{p}=0.063$ ).

The age of malnourished patients was significantly higher (mean \pm SEM age $78.0 \pm 1.6$ yrs) compared with the other two groups (at risk $75.6 \pm 0.5$ and well nourished $74.6 \pm 0.3$ yrs; ANOVA $\mathrm{p}<0.031)$.

When the 18 items of the MNA questionnaire were separately analysed, four of them qualified as negative correlates of age, as follows. Question A: Has food intake declined over the past 


\begin{tabular}{lrllll}
\hline TABLE 4 & $\begin{array}{l}\text { Differences in body composition, energy intake } \\
\text { and body functionality scores between Global } \\
\text { Initiative for Chronic Obstructive Lung Disease } \\
\text { (GOLD) stages }\end{array}$ \\
& GOLD I & GOLD II & GOLD III & GOLD IV & p-value \\
\hline Body score & $6.8 \pm 0.3$ & $6.6 \pm 0.2$ & $6.3 \pm 0.3$ & $5.5 \pm 0.3^{*}$ & 0.009 \\
$\begin{array}{l}\text { Energy score } \\
\text { Functionality } \\
\text { score }\end{array}$ & $8.0 \pm 0.2$ & $7.4 \pm 0.1$ & $7.6 \pm 0.2$ & $7.6 \pm 0.2$ & 0.229 \\
\hline
\end{tabular}

Data are presented as mean \pm SEM, unless otherwise stated. *: $p<0.05$ in post hoc test.

3 months due to loss of appetite, digestive problems, chewing or swallowing difficulties? $\left(\mathrm{r}_{\mathrm{s}}=-0.17 ; \mathrm{p}<0.001\right)$; question $\mathrm{C}$ : Mobility ( $\mathrm{rs}=-0.24 ; \mathrm{p}<0.001)$; question G: Lives independently ( $\mathrm{rs}=-0.27 ; \mathrm{p}<0.001)$; question $\mathrm{M}$ : How much fluid...is consumed per day? $(\mathrm{r} s=-0.13 ; \mathrm{p}=0.03)$ (online supplementary material). Multiple regression analysis demonstrated that only questions $\mathrm{C}$ and $\mathrm{G}$ of the MNA questionnaire were independently correlated with age (model $\mathrm{r}^{2}=0.108 ; \beta=-0.198$ and $\beta=-0.172 ; p=0.004$ and $p=0.013$, respectively).

Energy intake and body functionality scores were significantly and negatively correlated with age $(r=-0.16(p=0.008)$ and $r=-0.15(p=0.009)$, respectively), whereas body composition was not. Multiple regression analysis demonstrated that only body functionality was independently correlated with age (table 6).

Finally, body composition, energy intake and body functionality scores did not differ between sexes (data not shown).

\section{DISCUSSION}

The main finding of this study is that COPD severity and ageing are significantly, although weakly, correlated with different aspects of the nutritional status: disease severity correlated with body composition and body functionality, whereas ageing did so mainly with decreased body functionality. While BMI remains a primary index of malnutrition and disease severity, the MNA questionnaire allows a valuable insight into complexity of components of nutritional status and may provide useful clues for treatment strategies. In fact, our results suggest that prevention and treatment of body functionality deterioration might be the main objective of

\section{TABLE 5 Multiple ordinal regression analysis}

\begin{tabular}{lcc} 
& $\boldsymbol{\beta}$ & $\boldsymbol{p}$-value \\
\hline Body score & -0.186 & 0.005 \\
Energy score & 0.154 & 0.073 \\
Functionality score & -0.163 & 0.006 \\
\hline
\end{tabular}

Dependent variable: Global Initiative for Chronic Obstructive Lung Disease (GOLD) stage; independent variables: body composition, energy intake and body functionality scores. Model corrected for age. $r^{2}=0.073$.

\section{TABLE 6 Multiple regression analysis}

\begin{tabular}{lcc} 
& $\boldsymbol{\beta}$ & $\boldsymbol{p}$-value \\
\hline Body score & 0.011 & 0.868 \\
Energy score & -0.103 & 0.122 \\
Functionality score & -0.131 & 0.047 \\
\hline
\end{tabular}

Dependent variable: age; independent variables: body composition, energy intake and body functionality scores. Model corrected for Global Initiative for Chronic Obstructive Lung Disease (GOLD) stage. $r^{2}=0.037$

nutritional interventions, whatever their effects on body composition.

Our findings confirm and extend previous observations by other authors. First, it has been demonstrated that the prevalence of underweight increases with severity of COPD [12] and that fat-free mass decreases in advanced GOLD stages [19]. Furthermore, both gold standard and surrogate parameters of body composition, such as low fat-free mass [4], midthigh muscle cross-sectional area [11] and mid-arm muscle area [20], are better predictors of mortality than BMI. Secondly, our study demonstrates that energy intake is not correlated with disease severity. This is consistent with data from a systematic review, which indicated that nutritional support has no significant effect on anthropometric measures, lung function or exercise capacity in patients with stable COPD [21]. Furthermore, recent data [22] demonstrated that moderate-tosevere COPD patients report an adequate intake of main foods and macro- and micronutrients. However, other authors found that dietary counselling and higher caloric intake resulted in weight gain and improvement in outcome in COPD outpatients at risk of malnutrition [23].

Body composition score did not correlate with age. However, the sample of the present study only included patients aged $\geqslant 65$ yrs. This narrowed range may explain this lack of expected correlation. Indeed, muscle mass loss is a progressive component of ageing, exacerbated by limited physical activity and not linked to age-associated diseases [24]. Bioelectrical impedance analysis demonstrates a clear trend toward a reduction of lean mass with age [25]. In addition, a longitudinal study confirmed a significant decrease in fat-free mass and body water in both sexes from age 75 to 80 yrs, even in the absence of significant body weight changes [26].

Data in the literature about "body functionality" in COPD patients are sparse. The most considered body functionality indices are autonomy in activities of daily life, and the number and type of current pathologies that may influence malnutrition [9]. The present study demonstrated that this component of the nutritional status was correlated with both disease severity and aging. Data on elderly COPD showed that the following factors were more frequent among the malnourished patients compared with those identified as at risk for malnutrition: living alone, not living in one's own home, requiring daily community service and meals-on-wheels [27]. This is consistent with our observation of negative correlation between age and question $G$ (Lives independently) of the MNA. 
A potential weakness of the present study could be the age range (65-92 yrs), which precludes comparisons with younger patients. The present study was designed to focus on elderly patients with COPD. This represents a homogeneous setting, with patients sharing similar characteristics, and probably allows performance of observations and analysis targeted to this population, also taking into account the fact that a reasonably wide age range, including almost three decades (65-92 yrs), was studied. While it must be recognised that a comparison with younger subjects may have added valuable information, it must be underlined that COPD at a younger age is relatively uncommon or at earlier stage, and so it would have been hard to enrol significant numbers of much younger patients with similar clinical phenotypes.

The choice of any assessment instrument (including MNA) could be questionable, because many variables and, consequently, tools may be used to assess malnutrition. It has to be taken into account that no single measurement has emerged as gold standard in defining malnutrition in the elderly [9, 14]. However, the use of the MNA questionnaire seems a suitable choice because it explores all three determinants of the nutritional status [9], and the European Society of Parenteral and Enteral Nutrition endorsed it as a recommended screening tool in the elderly [14]. Another potential limitation of the study concerns the submission of the full MNA questionnaire to all patients, regardless of screening score. It should be considered that originally, the MNA was developed in its full version (18 items) and only subsequently the short form (that is the screening; six items) was developed [18]. The authors who developed the MNA pointed out that the MNA short form can be used with confidence; however, administering the full MNA might be more efficient in some settings [18]. The screening is only a way to save time in some clinical situations, while the full MNA is appropriate in all kinds of elderly patients. In addition, the statistical analysis shows the absence of difference between subjects who did or did not complete the full MNA (see Methods section).

MNA was originally designed as a composite tool in which various domains contribute to the final score [18]. As such, the individual validity of each domain may be questioned. However, previous studies on malnutrition in the elderly have shown that lower dietary score distinguishes between malnourished and at-risk populations better than body composition and body function domains of the MNA [28].

Several mechanisms may explain the finding that ageing and COPD determine malnutrition by acting on different aspects of the nutritional status. In COPD patients, both physical inactivity due to exercise intolerance [29] and systemic inflammation [3] may explain the prevalent loss of fat-free mass. In addition, the expansion of extracellular and intracellular water volumes, driven by hypoxaemia, may explain why malnutrition may occur despite normal weight [30]. However, in elderly subjects, weight loss and malnutrition are highly prevalent and variously depend upon physical, social and medical factors [7]. The observed negative correlation between ageing and energy intake might be due to nutritional (e.g. loss of taste, poor dentition, dysphagia, poor chewing and swallowing ability, poor appetite or food aversion) and social (e.g. living or eating alone or poverty) problems, and to decreased energy and inability to self feed. Furthermore, many age-related medical factors (comorbidity, polypharmacy, infections, fractures, dementia and physical disability) can contribute to a link between ageing and body functionality, as found in this study. Body functionality includes several variables that can be causes or effects of malnutrition at the same time. Nevertheless, as stated by CHEN et al. [31] "malnutrition in the elderly is a multidimensional concept encompassing physical and psychosocial elements. It is precipitated by loss, dependency, loneliness and chronic illness". With this perspective, the management of malnutrition in the elderly COPD can not only include "nutrients". Consistent with this and taking together the present results on correlations between GOLD stage, and age, Mobility (item C) and Subjective perception of health status (item P) appear susceptible to specific intervention, such as rehabilitation or treatment of depression. As a result, a pure nutritional intervention is highly unlikely to improve nutritional status and physical performance in COPD [32], while only an integrated multidimensional intervention centered on rehabilitation is likely to succeed. The favourable findings in both very old and frail patients [33] and in selected COPD populations [34, 35] support this conclusion. Within this setting, particular attention is warranted by depression as a factor susceptible of intervention: in fact, an association between malnutrition, as assessed by MNA, and depressive symptoms has been demonstrated [36].

In conclusion, the results of the present study suggest that severe COPD and ageing are independent and probably concurrent conditions leading to malnutrition. COPD influences aspects related to body composition, whereas both COPD and ageing contribute to poor body functionality. The present findings should be considered preliminary, due to the cross-sectional design and the small size of the correlation coefficients. Nevertheless, they probably contribute to our understanding of the complex relationship between COPD severity, ageing and nutritional status.

\section{STATEMENT OF INTEREST}

None declared.

\section{ACKNOWLEDGEMENTS}

The ECCE participating centres and study investigators are as follows. Dipartimento Biomedico di Medicina Interna e Specialistica, Università di Palermo, Palermo, Italy (chief: V. Bellia; investigators: S. Battaglia, G. Paglino, R. Catania, M. Spatafora, N. Scichilone); Università Campus Biomedico, Rome, Italy (chief: R. Antonelli Incalzi; investigators: S. Scarlata, E. Conte); Università Cattolica, Rome (chief: R. Pistelli; M. Andreani, F. Baldari); Medicina Respiratoria, Spedali Civili, Brescia, Italy (chief: V. Grassi; investigators: C. Tantucci, S. Ghibelli, S. Casella); Università degli Studi Federico II, Naples, Italy (chief: F. Rengo; investigators: C. Visconti); Azienda ULSS13, Mirano, Italy (chief: A. Cester; investigators: E. Vitale); Policlinico Ospedale D'Avanzo, Foggia, Italy (chief: M.P. Foschino; investigators: I. Ventura, M.G. Cagnazzo); Università S.Cuore-CEMI, Rome (chief: R. Bernabei; investigators: F. Cerullo, C. Palmacci); Pio Albergo Trivulzio, Milano (chief: P. Berardinelli; investigators: E. Carotenuto); Policlinico di Bari, Bari, Italy (chief: O. Resta; investigators: G. Di Gioia, C. Scoditti); Università di Perugia, Perugia, Italy (chief: L. Casali; investigators: C. Gradoli); Fondazione San Raffaele, Cittadella della Carità, Taranto, Italy (chief: G. Guadalupi); Università degli Studi di Firenze, Florence, Italy (chief: G. Masotti; investigators: M. Di Bari); INRCA Istituto di 
Ricovero e Cura a Carattere Scientifico, Cosenza, Italy (chief: B. Mazzei; investigators: C. Zottola); Ospedale San Giuseppe Moscati, Taranto (chief: A. Giusti; investigators: C. Spada).

\section{REFERENCES}

1 Rabe KF, Hurd S, Anzueto A, et al. Global strategy for the diagnosis, management, and prevention of chronic obstructive pulmonary disease: GOLD executive summary. Am J Respir Crit Care Med 2007; 176: 532-555.

2 Agusti AG, Noguera A, Sauleda J, et al. Systemic effects of chronic obstructive pulmonary disease. Eur Respir J 2003; 21: 347-360.

3 King DA, Cordova F, Scharf SM. Nutritional aspects of chronic obstructive pulmonary disease. Proc Am Thorac Soc 2008; 5: 519 523.

4 Schols AM, Broekhuizen R, Weling-Scheepers CA, et al. Body composition and mortality in chronic obstructive pulmonary disease. Am J Clin Nutr 2005; 82: 53-59.

5 Landbo C, Prescott E, Lange $\mathrm{P}$, et al. Prognostic value of nutritional status in chronic obstructive pulmonary disease. Am J Respir Crit Care Med 1999; 160: 1856-1861.

6 Ranieri P, Bianchetti A, Margiotta A, et al. Predictors of 6-month mortality in elderly patients with mild chronic obstructive pulmonary disease discharged from a medical ward after acute nonacidotic exacerbation. J Am Geriatr Soc 2008; 56: 909-913.

7 Hickson M. Malnutrition and ageing. Postgrad Med J 2006; 82: 2-8.

8 Pirlich M, Schutz T, Kemps M, et al. Social risk factors for hospital malnutrition. Nutrition 2005; 21: 295-300.

9 Donini LM, Savina C, Rosano A, et al. Systematic review of nutritional status evaluation and screening tools in the elderly. J Nutr Health Aging 2007; 11: 421-432.

10 World Health Organization. Physical Status: the Use and Interpretation of Anthropometry. Report of a WHO Expert Committee. WHO Technical Report; Series 854. Geneva, World Health Organization, 1995. http://whqlibdoc.who.int/trs/WHO_ TRS_854.pdf.

11 Marquis K, Debigare R, Lacasse $Y$, et al. Midthigh muscle crosssectional area is a better predictor of mortality than body mass index in patients with chronic obstructive pulmonary disease. Am J Respir Crit Care Med 2002; 166: 809-813.

12 Vestbo J, Prescott E, Almdal T, et al. Body mass, fat-free body mass, and prognosis in patients with chronic obstructive pulmonary disease from a random population sample: findings from the Copenhagen City Heart Study. Am J Respir Crit Care Med 2006; 173: 79-83.

13 Bouillanne O, Morineau G, Dupont C, et al. Geriatric Nutritional Risk Index: a new index for evaluating at-risk elderly medical patients. Am J Clin Nutr 2005; 82: 777-783.

14 Kondrup J, Allison SP, Elia M, et al. ESPEN guidelines for nutrition screening 2002. Clin Nutr 2003; 22: 415-421.

15 Vellas B, Guigoz Y, Garry PJ, et al. The Mini Nutritional Assessment (MNA) and its use in grading the nutritional state of elderly patients. Nutrition 1999; 15: 116-122.

16 Antonelli Incalzi R, Corsonello A, Pedone C, et al. Chronic renal failure: a neglected comorbidity of COPD. Chest 2010; 137: 831-837.
17 Celli BR, MacNee W, Agusti A. Standards for the diagnosis and treatment of patients with COPD: a summary of the ATS/ERS position paper. Eur Respir J 2004; 23: 932-946.

18 Guigoz Y. The Mini Nutritional Assessment (MNA) review of the literature - what does it tell us? J Nutr Health Aging 2006; 10: 466485 .

19 Ischaki E, Papatheodorou G, Gaki E, et al. Body mass and fat-free mass indices in COPD: relation with variables expressing disease severity. Chest 2007; 132: 164-169.

20 Soler-Cataluna JJ, Sanchez-Sanchez L, Martinez-Garcia MA, et al. Mid-arm muscle area is a better predictor of mortality than body mass index in COPD. Chest 2005; 128: 2108-2115.

21 Ferreira IM, Brooks D, Lacasse $Y$, et al. Nutritional supplementation for stable chronic obstructive pulmonary disease. Cochrane Database Syst Rev 2005; 2: CD000998.

22 de Batlle J, Romieu I, Anto JM, et al. Dietary habits of firstly admitted Spanish COPD patients. Respir Med 2009; 103: 1904-1910.

23 Weekes CE, Emery PW, Elia M. Dietary counselling and food fortification in stable COPD: a randomised trial. Thorax 2009; 64: 326-331.

24 Roubenoff R. Sarcopenia and its implications for the elderly. Eur Clin Nutr 2000; 54: Suppl. 3, S40-S47.

25 Buffa R, Floris G, Marini E. Migration of the bioelectrical impedance vector in healthy elderly subjects. Nutrition 2003; 19: 917-921.

26 Dey DK, Bosaeus I, Lissner L, et al. Changes in body composition and its relation to muscle strength in 75-year-old males and females: a 5-year prospective follow-up study of the NORA cohort in Goteborg, Sweden. Nutrition 2009; 25: 613-619.

27 Odencrants S, Ehnfors M, Ehrenberg A. Nutritional status and patient characteristics for hospitalised older patients with chronic obstructive pulmonary disease. J Clin Nurs 2008; 17: 1771-1778.

28 Feldblum I, German L, Castel H, et al. Characteristics of undernourished older medical patients and the identification of predictors for undernutrition status. Nutr J 2007; 6: 37.

29 Wagner PD. Skeletal muscles in chronic obstructive pulmonary disease: deconditioning, or myopathy? Respirology 2006; 11: 681-686.

30 Faisy C, Rabbat A, Kouchakji B, et al. Bioelectrical impedance analysis in estimating nutritional status and outcome of patients with chronic obstructive pulmonary disease and acute respiratory failure. Intensive Care Med 2000; 26: 518-525.

31 Chen CC, Schilling LS, Lyder CH. A concept analysis of malnutrition in the elderly. J Adv Nurs 2001; 36: 131-142.

32 Ferreira IM, Brooks D, Lacasse Y, et al. Nutritional support for individuals with COPD: a meta-analysis. Chest 2000; 117: 672-678.

33 Fiatarone MA, O'Neill EF, Ryan ND, et al. Exercise training and nutritional supplementation for physical frailty in very elderly people. N Engl J Med 1994; 330: 1769-1775.

34 Slinde F, Gronberg AM, Engstrom CR, et al. Individual dietary intervention in patients with COPD during multidisciplinary rehabilitation. Respir Med 2002; 96: 330-336.

35 Steiner MC, Barton RL, Singh SJ, et al. Nutritional enhancement of exercise performance in chronic obstructive pulmonary disease: a randomised controlled trial. Thorax 2003; 58: 745-751.

36 Smoliner $\mathrm{C}$, Norman $\mathrm{K}$, Wagner $\mathrm{KH}$, et al. Malnutrition and depression in the institutionalised elderly. Br J Nutr 2009; 102: 1663-1667. 